\title{
Bourdieu, Baudrillard e Bauman: O Consumo Como Estratégia de Distinção
}

\section{Daniel Gambaro}

Graduado em Comunicação Social Rádio e TV pela Universidade Anhembi Morumbi. Mestre em Meios e Processos Audiovisuais pela ECA/USP. Professor da Escola de Comunicação da Universidade Anhembi Morumbi e pesquisador de rádio. E-mail:

dgambaro@anhembimorumbi.edu.br
Resumo: A partir de três textos de Bourdieu, Baudrillard e Bauman, o presente artigo pretende refletir sobre a evolução do consumo econômico e cultural como forma de distinção entre as classes sociais no decorrer do século 20 . Serve como exercício de análise de pontos em comum entre esses autores, em suas reflexões sobre os usos e posses de objetos e crítica à definição dos status social. Parte-se da premissa que cada texto representa um momento diferente na fase de aceleração ditada pelo capitalismo: da distinção entre classes baixa, média e alta nas esferas produtivas e de consumo, à manutenção de um status quo, resultado de práticas de consumo de um momento de alta obsolescência dos produtos, tanto técnicos como culturais.

Palavras-chave: Consumo, distinção, classe social, modernidade líquida

Abstract: The present article intends to discuss on the evolution of the economic and cultural consumption as means of distinction among social classes during the 20th century, using as basis three texts from Bourdieu, Baudrillard and Bauman. It actually is an exercise of analysis of the converging points between the three theorists, which can be found on their debates about the uses and possession of objects and critics to the definition of the social status. The proposed text has as initial premise that each text represents a different moment on the phase of acceleration imposed by the capitalism: from the distinction between the lower, middle and upper classes on the production and consumption spheres, to the maintenance of the status quo resulting of consumption practices on a momento of high obsolescence of both technical and cultural products.

Keywords: Consumption, distinction, social classes, liquid modernity

\section{Introdução}

O presente ensaio tenta fazer aproximações entre três teóricos da sociologia que discutem questões do consumo estratificado em classes sociais. Não se trata, no entanto, de uma visão abrangente sobre a obra desses autores, e sim um exercício de reflexão que parte de três extrações do conjunto de seus livros. Em outras palavras, é um olhar bastante circunstancial sobre apenas alguns pontos das teorias de Pierre Bourdieu, Jean Baudrillard e Zygmunt Bauman.

Os textos que aqui serviram de referência analisam principalmente o comportamento da classe média: da motivação das escolhas, do gosto, às conseqüências do consumo realizado por determinado estrato social. Os pontos convergentes e divergentes nos textos escolhidos desses teóricos serão delineados, enquanto tentamos definir um caminho que mostre a evolução do consumo de 
objetos como elemento de distinção social e símbolo de pertencimento a grupos sociais.

Temos que diferenciar, no entanto, as abordagens proporcionadas por cada autor. Em Gostos de classe e estilos de vida, Pierre Bourdieu parece lançar um olhar mais panorâmico sobre a construção do gosto da classe média. Sem ter um caráter histórico, o texto aborda o momento de emergência de uma classe "pequeno-burguesa", composta por trabalhadores de outras áreas que não as fábricas. Assim, coloca em comparação com essa classe média as classes alta e baixa, e como os diferentes modos de aquisição de cultura - o gosto estético, principalmente - são resultado de gostos próprios das classes, local onde as escolhas são também constituintes de diferenciação.

Jean Baudrillard, em Função-signo e lógica de classe, percorre caminho análogo, porém sem olhar diretamente para esse momento de emergência da classe média. Baudrillard acresce à discussão elementos que se aproximam da semiologia, ao tentar definir os diferentes significados que os objetos assumem de acordo com a classe social estudada. Assim como em Bourdieu, encontramos o consumo material como elemento diferenciador, ou, mais que isso, de exclusão.

Podemos afirmar que o terceiro texto, A cultura do lixo, de Zygmunt Bauman, vem atualizar e complementar essas reflexões quando colocamos os três escritos lado a lado. Bauman é um sociólogo da atualidade, que olha para a modernidade tardia (ou modernidade líquida, para usar o termo dele) com grande realismo e, muitas vezes, com um tom pessimista. O sociólogo polonês observa uma situação estabelecida, em que o consumo deixa de ser meramente um elemento de distinção para ser o elemento de inclusão por excelência: se a modernidade traz vários problemas consigo, o consumo - força motriz do capitalismo - se traveste como única solução (ou única porta de saída). Assim, tudo se torna ainda mais transitório, e conseqüentemente mais descartável.

Levando a análise aqui proposta ao limite, vamos tentar demonstrar como o texto de Bauman, portanto, complementa os outros dois. Na verdade, seguiremos uma trilha em que as bases são lançadas pelos dois primeiros textos: assim, as questões de Bauman são tratadas como percepções da evolução de um estado apontado pelos teóricos franceses ainda em meados do século passado.

\section{Bourdieu e Baudrillard: gosto, significado do consumo e estratégias de distinção}

Pierre Bourdieu afirma que o habitus, princípio gerador de todas as práticas, reside no gosto individual, mas acaba por se assemelhar entre todos os membros de uma mesma classe: o habitus define, portanto, os estilos de vida das classes sociais. Para o sociólogo, é possível identificar então uma repetição nos padrões de escolha dos indivíduos: cada esfera do estilo de vida --uma prática social, um objeto consumido, ou uma propriedade - é representante quase sempre também outra esfera. No limite, pertencer a um grupo significaria excluir tudo o que pertence a outro grupo, e o conjunto de escolhas, que definem o estilo de vida, passa a ser similar a toda uma classe.

Os gostos, assim como as necessidades, variam conforme o nível econômico. Enquanto as classes mais baixas têm como estilo de vida a realização das necessidades básicas do mundo, as classes mais abastadas, que possuem melhores condições de satisfazer essas prioridades, buscam necessidades que, para os menos favorecidos, são luxos irrealizáveis. Esses luxos são objetos de conforto que se tornam necessidade. As práticas realizadas nessas condições se constituem "numa experiência liberada da urgência e na prática de atividades que tenham nelas mesmas sua finalidade" (BOURDIEU, 1983: p.87). 


\begin{abstract}
"O estilo de vida das classes populares deve suas características fundamentais, compreendendo aquelas que podem parecer como sendo as mais positivas, ao fato de que ele representa uma forma de adaptação à posição ocupada na estrutura social" [O que encerra uma forma de reconhecimento dos valores dominantes] "O que separa as classes populares das outras classes é menos [...] a intenção objetiva de seu estilo [que] os meios econômicos e culturais que elas podem colocar em ação para realizá-la". (BOURDIEU, 1983: p.100)
\end{abstract}

Bourdieu avança em uma crítica ao consumo cultural. Para o autor, as classes médias se distanciam do consumo de uma produção simbólica massiva em busca do que seria uma "arte legítima". No entanto, na falta de subsídios para compreender as vanguardas artísticas, satisfazem-se em adquirir essas competências (ou parte delas) na escola, nos meios de comunicação ou na vivência de experiências - o que tornaria o conhecimento incompleto. "As diferentes classes sociais se distinguem menos pelo grau em que reconhecem a cultura legítima do que pelo grau em que elas a conhecem" (BOURDIEU, 1983: p.94), isto é, apesar de não entender o sentido da obra, essas classes reconhecem que elas são importantes.

\footnotetext{
“Não basta lembrar, contra o relativismo semi-erudito, que a 'cultura' dominada está marcada, de ponta a ponta, pela cultura dominante e pela desvalorização da qual ela é objeto. A própria cultura dominante deve também suas propriedades mais fundamentais o fato de que ela se define, sem cessar, negativamente em relação às 'culturas' dominadas" (BOURDIEU, 1983: p.99).
}

De modo análogo, os membros das classes populares "são também desapossados dos instrumentos de apropriação simbólica das máquinas a que eles servem [os instrumentos de produção]" (BOURDIEU, 1983: p.100), ou seja, não possuem o capital cultural necessário para tomar propriedade sobre os objetos técnicos. As classes populares aprendem na fábrica o respeito por saberes "inúteis e desinteressados" da mesma forma que o aprendem na escola, mas não são detentoras desse conhecimento: vivenciam uma espécie de conformismo dado apenas pelo reconhecimento. São, então, dominadas pelas máquinas e pela classe dominante detentora dos meios legítimos de propriedade - o conhecimento teórico - "e reencontram a cultura como um princípio de ordem que não tem necessidade de desmontar sua utilidade prática para ser justificado" (BOURDIEU, 1983: p.102). A mesma lógica que se aplica aos meios técnicos vale para a obra de arte: esta se legitima a partir do corte entre os detentores dos saberes práticos e do conhecimento teórico, entre a ciência e a técnica.

Já ao tratar da classe média, do pequeno burguês, Bourdieu define uma fronteira na ordem do estilo de vida. Estes possuem uma boa vontade cultural, que é uma pretensão de obter um degrau maior de cultura. Por ser uma classe que emergiu daquela popular, resta à classe média adquirir a cultura: daí sua preferência pelas artes médias, industrializadas (como Theodor Adorno indica em $A$ indústria cultural $^{1}$, o cinema, o rádio e a fotografia ganham, para a burguesia, status de arte em antítese à arte "autêntica").

${ }^{1}$ ADORNO, T.W; HORKHEIMER, M.. A indústria cultural: o iluminismo como mistificação de massas. Em: Teoria da Cultura de Massa. Rio de Janeiro: Paz e Terra, 1978, pág.164
Bourdieu alerta que é preciso conhecer os sistemas de classificação e as técnicas de identificação dos símbolos de distinção (social e de classe): desde os bens materiais de maior ou menor qualidade, até os lugares freqüentados, a música consumida, a estação de rádio ouvida, etc. "... índices da 'classe', da hierarquia social das pessoas e dos objetos, que define o que se chama bom gosto". (BOURDIEU, 1983: p.111)

“Essa mistura de gêneros, essa confusão de ordens, essa espécie de bricabraque onde se alinham os produtos legítimos 'fáceis ou ultrapassados', fora da moda, desclassificados, portanto, desvalorizados - posto que um símbolo de distinção apropriado com atraso perde tudo o que faz seu valor distintivo - e os produtos 
'médios' - do campo de produção em massa, é a imagem objetivada de uma cultura pequeno-burguesa." (BOURDIEU, 1983: p.112)

A hierarquia social a que Bourdieu se refere não é somente aquela que define estratos amplos como classes alta, média e baixa: dentro dessas estratificações, é possível ainda identificar uma elite, que domina determinado campo de produção artística.

Em resumo, o que mais interessa aqui, entre os apontamentos de Pierre Bourdieu, são as formas de apropriação cultural da classe pequeno-burguesa: ao mesmo tempo em que ela se afasta da conformação e hedonismo das classes populares, tenta se aproximar das classes altas, das vanguardas e do consumo do que é "tradicionalmente bom". Na ausência de uma competência natural para realizar essa apropriação, o pequeno-burguês acaba frequentando círculos e consumindo objetos mais próximos de sua própria realidade. Importa, também, a atualidade dos objetos e serviços consumidos, pois o velho significa perda de status.

Acrescenta-se à discussão alguns pontos levantados por Jean Baudrillard. Como dito anteriormente, este teórico trata em seu texto especialmente do consumo de objetos - bens materiais - como elementos diferenciadores do estilo de vida. Ambos os textos se aproximam, mas é preciso lembrar que Bourdieu aponta, logo no começo de seu texto, que

“O estilo de vida é um conjunto unitário de preferências distintivas que exprimem, na lógica específica de cada um dos subespaços simbólicos, mobília, vestimentas, linguagem ou hexis corporal, a mesma intenção expressiva, princípio de unidade de estilo que se entrega diretamente à intuição e que a análise destrói ao recortá-lo em universos separados". (BOURDIEU, 1983: p.83/84)

Baudrillard, para falar do consumo na era moderna, afirma que desde sempre o consumo de bens é fruto de uma diferenciação, "é uma função social de prestígio e de distribuição hierárquica" (BAUDRILLARD, 1996: p.10). O valor de troca supera a simples necessidade, o valor de uso, fornecendo a possibilidade de distinção social e de uma ideologia a ela ligada. Assim, o objeto não é somente uma função da necessidade: uma verdadeira análise deve levar em conta os motivos de sua existência, o significado atribuído à troca: "o valor de troca-signo é fundamental" (BAUDRILLARD, 1996: p.10).

De certa forma, Baudrillard se aproxima do conceito de Bourdieu de necessidade básica: o objeto não é simplesmente a satisfação dessa necessidade, é antes o local de uma produção, para satisfazer demandas que surgem (como novas) conforme se ascende na escala social. Assim, é necessário levar em conta não apenas os objetos que uma classe tem em comparação à outra, mas também a quantidade e, mais importante, a qualidade desse objeto, sua disposição e qual a o uso final dado a ela.

"Podemos certamente, num primeiro tempo, considerar os objetos em si próprios e a sua soma como índice de pertença social, mas é muito mais importante considerá-los, na sua escolha, organização e prática, como o suporte de uma estrutura global do ambiente circundante, que é simultaneamente uma estrutura ativa de comportamento." (BAUDRILLARD, 1996: 17)

Nessa perspectiva, Baudrillard aponta que não é possível, portanto, atribuir diretamente um objeto a uma classe social (como fazem as pesquisas analíticas dos produtos). Baudrillard identifica dois grupos: um de pertença, que usa o objeto como que por direito adquirido, e o de referência, que olha para o primeiro 
grupo e tenta se assemelhar ou diferenciar, promovendo daí um jogo de distinção e conformidade. Há necessidade de parênteses: apesar de Bourdieu dizer que as escolhas em uma esfera, em um estilo de vida, refletem as outras, não há contradição com Baudrillard. Baudrillard diz que não é o objeto uma exclusividade de um grupo social, e sim o uso feito por esse grupo. Bourdieu, ao diferenciar as escolhas, as trata como um conjunto que coloca lado a lado bens e usos: deduz-se daí uma série de articulações que, no final, representariam a distinção proposta por ambos os teóricos. No entanto, a perspectiva de Bourdieu torna ocultas certas disparidades e contrastes que ficam mais explícitas em Baudrillard.

Para Jean Baudrillard, os objetos - e os usos a eles atribuídos - são signos de uma pretendida ascensão social, uma necessidade de pertencimento a um grupo. Pela lógica capitalista, essa é a força motriz que permite as realizações e invoca o consumo como elemento de progresso. O teórico, no entanto, alerta que essa busca por mobilidade revestida nos objetos apenas oculta um movimento cíclico que, ao invés de permitir, bloqueia uma real subida na escala social. Os motivos são variados, o que torna necessário centrar a discussão apenas naquele que parece ser mais relevante, especialmente pelo respaldo encontrado no texto de Zygmunt Bauman: a constante renovação dos objetos.

Como Bourdieu avisa, a suplantação de uma necessidade significa a imediata criação de outra que, para um indivíduo em nível inferior da escala social, não passa de um supérfluo, de um luxo. Mas essa criação de luxos se torna ela mesma uma necessidade das classes abastadas, assim como substituir o que está atrasado e velho. Baudrillard envereda pelo mesmo caminho, ao afirmar que a distinção e a exclusão - ocorre pela renovação dos bens consumíveis supérfluos: se uma classe inferior consegue ter acesso a um bem (objeto, vestuário, uma moda) que era exclusiva de uma classe superior, esse objeto é então substituído. A satisfação da necessidade daquele indivíduo mais abastado é facilmente superada, mas não a da classe inferior. Dessa forma, a moda se torna um fator de inércia social dada a rápida atualização que ela exige, criando a ilusão de mudança e progresso.

Além disso, Baudrillard também indica o modo de aquisição cultural como forma de diferenciação. Usando como exemplo a TV, ele primeiro nota que o simples fato de possuir um aparelho já significa um elemento distintivo. Vamos lembrar que o texto foi escrito em um momento cujo acesso aos aparelhos ainda representava um custo muito alto para certas camadas sociais. Mas, se atualizarmos isso aos dias de hoje, o grau de sofisticação do equipamento, aliado ao design e ao preço, é realmente um elemento de diferenciação.

O que o teórico não deixa de notar é que o conteúdo adquirido também é um elemento de distinção: a classe média, neste caso, usaria a TV como forma de aquisição de conhecimento (como antecipado por Bourdieu), ainda que parcial. "Nas sociedades industriais modernas, raramente o objeto é um puro feitiço: geralmente, o imperativo técnico de funcionamento impõe-se... o valor de uso é, no fundo, um álibi para o valor de troca-signo". (BAUDRILLARD, 1996: p.40). O que justifica afirmar que o consumo cultural através de um meio de comunicação como a TV tem um duplo significado: qual conteúdo o indivíduo escolhe receber (documentários, novelas, desenhos) e como ele recebe o conteúdo (via cabo, antena, satélite, numa TV simples ou numa TV de última geração).

Em suma, o principal ponto de aproximação entre Baudrillard e Bourdieu fica por conta das estratégias de consumo (de objetos ou de arte) como estratégias também de diferenciação. Se Bourdieu fala de uma cultura "por direito" oposta a uma cultura referenciada, Baudrillard enxerga nos meandros dessa oposição os sinais de embate, se não de uma luta de classe, de uma perspectiva de movimentação, de "progresso capitalista" entre as classes sociais. E, como determinante das diferenças, o objeto pelo qual os significados são adquiridos: para Bourdieu, por exemplo, não importa que as classes alta e média frequentem o teatro, uma vez 
que o tipo de aproveitamento, as preferências entre as obras, serão diferentes. 0 mesmo se daria no consumo dos objetos. E aqui Baudrillard acrescenta bastante, ao afirmar que é importante analisar como cada indivíduo usa o objeto.

Este é o momento propício para trazer Bauman à discussão. Em seus textos, ele indica o grande problema da modernidade líquida como a geração de lixo pela alta obsolescência dos objetos e das pessoas.

\section{Bauman e a modernidade líquida.}

Zygmunt Bauman é reconhecido como um dos mais importantes sociólogos da atualidade. Em geral, seus textos tratam do conceito - por ele cunhado - de modernidade líquida: o conceito de infinitude que norteou as ações humanas durante muitos séculos, inclusive na passagem da idade média para a era moderna, começa a desaparecer junto à importância da religião, da família, e de outros sistemas de controle social. A segurança oferecida pelo eterno começou a ser corroída pela modernidade, "quando os seres humanos se puseram a 'derreter tudo que é sólido' e a 'profanar tudo que é sagrado'”. (BAUMAN, 2004: p.119).

Esse desmanche leva à fase líquida da era moderna, em que a vida individual se carrega de importância e passamos a viver uma transitoriedade universal.

\footnotetext{
"Nada no mundo se destina a permanecer, muito menos para sempre [...] nada é necessário de fato, nada é insubstituível [...] tudo deixa a linha de produção com um prazo de validade afixado [...] A modernidade líquida é uma civilização do excesso, da superfluidade, do refugo e da sua remoção". (BAUMAN, 2004: p.120).
}

Temos, aqui, um paralelo importante com Baudrillard, quando ele fala da superfluidade dos objetos

“... os objetos [supérfluos, decorativos] nunca se esgotam naquilo para que servem, e é neste excesso de presença que ganham a sua significação de prestígio" (BAUDRILLARD, 1996: p.12)

\footnotetext{
"Os setores de vestuário, aparelhos domésticos, automóvel, apartamento obedecem todos atualmente a normas de renovação acelerada, mas cada um segundo o seu ritmo - variando, aliás, a obsolescência relativa conforme as categorias sociais." (BAUDRILLARD, 1996: 18)
}

Ao analisar a contemporaneidade, Bauman nota que vivemos um ritmo vertiginoso de renovação, que envelhece os objetos mesmo antes deles saírem da fábrica: tudo tem data de validade afixada. $E$ isso vale tanto para os objetos como para um movimento cultural, uma obra de arte, uma relação comercial, ou entre países, e mesmo uma relação amorosa.

“O ritmo vertiginoso da mudança desvaloriza tudo o que possa ser desejável e desejado hoje, assinalando-o desde o início como o lixo de amanhã, enquanto o medo do próprio desgaste que emerge da experiência existencial do ritmo estonteante da mudança instiga os desejos a serem mais ávidos, e a mudança, mais rapidamente desejada..." (BAUMAN, 1996: p.135)

Segundo o teórico polonês, usamos os mais variados recursos para acelerar as satisfações das necessidades. O crédito financeiro, por exemplo, como uma ferramenta que permite conseguir mais rapidamente o que se deseja. $O$ ponto nevrálgico da discussão é que essas necessidades não são outras senão aquelas 
criadas pelo capital, e elas são renovadas no mesmo ritmo alucinante em que são satisfeitas. Quando os nascimentos de desejos são abreviados, e o tempo até sua satisfação também se torna mais curto, o resultado é que "abreviam o tempo de vida dos objetos de desejo, ao mesmo tempo que suavizam e aceleram sua viagem em direção à pilha de lixo". (BAUMAN, 1996: p.137/8). É sobre essa superfluidade que trata também Baudrillard, escrevendo no período que seria o princípio dessa forte aceleração que vivemos de meados ao final do século XX. Nesse caso, o fútil e o funcional se confundem: o design passa a ditar as regras de construção dos objetos, a moda torna-se um elemento fundamental, e o supérfluo ganha status de primeira necessidade.

“...o objeto funcional aparenta ser decorativo, reveste-se de inutilidade ou dos disfarces da moda - o objeto fútil e gracioso carrega-se de função prática... estaríamos perante um simulacro funcional, por detrás do qual os objetos continuariam a desempenhar seu papel de discriminantes sociais" (BAUDRILLARD, 1996: p.13).

Para Bauman, viver na modernidade líquida significa não ter hábitos, não estar preso a passados e ter 'identidades mutáveis', que podem ser 'trocadas' quando em desuso ou fora de moda. A cultura líquido-moderna é uma cultura do desengajamento, da descontinuidade e do esquecimento, que deixa para trás o saber e a acumulação. Não há espaço para ideais. E, mais intrigante, manterse atualizado, não ser redundante, é o único modo de se manter afastado do caminho ao lixo. Ter o último produto, a última moda, assistir ao que todos assistem, considerar belo aquilo que a maioria gosta, são atitudes comuns na era líquido-moderna para combater o medo da rejeição. Ou, como diria Bourdieu:

\footnotetext{
"Afirmação de um poder sobre a necessidade dominada, [o estilo de vida] encerra sempre a reivindicação de uma superioridade legítima sobre aqueles que, não sabendo afirmar esse desprezo pelas contingências no luxo gratuito e no desperdício ostentatório, permanecem dominados pelos interesses e as urgências mundanas" (BOURDIEU, 1983: p.88)
}

Para Bourdieu, as classes mais abastadas, que há muito já superaram as necessidades mundanas, usam o consumo de supérfluos como elemento de distinção e distanciamento social; para Bauman, isso é uma forma de combater o medo de rejeição por usar algo que já é ultrapassado. Para Baudrillard, "a inovação formal em matéria de objetos não tem como fim um mundo ideal dos objetos, mas um ideal social - o das classes privilegiadas, e que é o de reatualizar perpetuamente o seu privilégio cultural" (BAUDRILLARD, 1996: p.31). Em nota o autor afirma que... "a inovação técnica - real - não tem como fim uma economia real, mas sim o jogo da distinção social” (BAUDRILLARD, 1996: p.33); para, então, terminar no lixo.

\section{Digressões finais}

Jean Baudrillard se pergunta se não estariam algumas classes destinadas à salvação pelo consumo, em substituição à salvação pelo domínio dos meios de produção, enquanto as classes abastadas caminham para o local da responsabilidade, de decisão econômica e política. $O$ autor se pergunta ainda se algumas classes não estariam votadas a alcançar a salvação nos objetos - uma moral dos escravos em oposição a uma moral dos senhores.

“... é absurdo falar de uma 'sociedade de consumo' como se o consumo fosse um sistema de valores universal, próprio de todos os homens, uma vez que fundado na satisfação das necessidades individuais. Na verdade, trata-se de 
uma instituição e de uma moral e, a este título, em qualquer sociedade passada ou futura, de um elemento da estratégia de poder". (BAUDRILLARD, 1996: p.33)

Assim como Baudrillard, Bourdieu analisa o jogo de poder - especialmente na esfera cultural, em que as práticas de aquisição interferem até mesmo nos significados das obras e das artes. "Ainda que se manifeste como universal, a disposição estética se enraíza nas condições de existência particulares... ela constitui uma dimensão, a mais rara, a mais distintiva, a mais distinguida, de um estilo de vida" (BOURDIEU, 1983: p.120/121).

É interessante notar que Bauman, escrevendo cerca de 50 anos depois, delega a um segundo plano as relações de luta de classe: ele trata a diferenciação e distinção como geradores de exclusão. $O$ autor, no entanto, não fornece caminhos possíveis: sua crítica, que se baseia essencialmente no consumo desvairado, apenas aponta os novos modos de vida da humanidade.

Se encararmos o texto de Bauman como uma atualização conceitual dos outros dois escritos, percebemos que o mero consumo de bens simbólicos e materiais se tornou menos, hoje, elemento de distanciamento entre as classes alta e média. $\mathrm{Na}$ verdade, ambas comporiam esse núcleo que luta para se reciclar, para não se tornar redundante - a redundância é local por excelência dos menos favorecidos, dos pobres. Os usos atribuídos aos objetos, esses sim, e a velocidade de troca, se tornaram os verdadeiros definidores do pertencimento a uma elite, da inclusão. A luta de classe, de ascensão na cadeia (proposta em Baudrillard) se tornou uma luta (da classe média principalmente) para não virar refugo, para não ir parar na lata do lixo da modernidade.

\section{Referências Bibliográficas}

BAUMAN, Zygmunt. A cultura do lixo. Em: Vidas Desperdiçadas. Rio de Janeiro: Jorge Zahar Editor, 2004, pág.117-164.

BAUDRILLARD, J.Função-signo e lógica de classe. Em: A Economia Política dos Signos. São Paulo: Editora Martins Fontes, 1996. Pág. 9-49.

BOURDIEU, Pierre. Gostos de classe e estilos de vida. Em: ORTIZ, Renato (org). Pierre Bourdieu: Sociologia. São Paulo: Ática, 1983. pag. 82-121 